\title{
Benthic foraminifera: \\ The validity of living, dead or total assemblages for the interpretation of palaeoecology
}

\author{
JOHN W. MURRAY \\ Department of Geology, University of Exeter, Exeter, Devon
}

\begin{abstract}
Data on modern foraminifera provide the basis for the palaeoecological interpretation of fossil forms. The validity of the use of living, dead, and total (living plus dead) assemblages is discussed. It is concluded that ecological studies can be carried out only on living assemblages and that it is important to determine the production and postmortem influences which lead to the formation of the dead assemblage. The use of total assemblages is shown to be ill-founded.
\end{abstract}

\section{INTRODUCTION}

In current literature on surveys of modern benthic foraminifera results are reported in terms of living, dead, and living plus dead (=total) assemblages. Invariably, these results are produced by palaeontologists with the object of building up a detailed picture of modern distributions and ecology in order to aid the interpretation of the palaeoecology of fossil faunas. To make the best use of this information it is necessary to understand the differences between these types of assemblages.

In the majority of studies carried out before the introduction of the rose Bengal staining method by Walton (1952), no attempt was made to differentiate living from dead foraminifera. Sample counts were made, usually of 250-300 specimens, and it was assumed that these assemblages were the product of the environment in which they were found. They were total assemblages in that they included both living and dead individuals without differentiating them. However, as many of these samples were taken with corers and poorly closing grabs (e.g. orange peel grab) the surface layer containing most of the living individuals was probably lost during the sampling process. Hence, many of these can be regarded as essentially dead assemblages.

The idea of using a biological stain to differentiate living from dead Foraminifera had been tried by several authors prior to 1952, as discussed by Walton. However, the advantages of using rose Bengal are that it is not acidic so that no harm is done to calcareous tests and it is simple and effective. Alongside the introduction of this staining technique there was an improvement in the quality of sampling equipment to ensure better recovery of the surface veneer of sediment.

Since 1952, a large number of studies have been carried out using rose Bengal to differentiate forms presumed to be alive at the time of sampling from those presumed to be dead. More recently, Sudan Black B has been used for the same purpose (Walker et al., 1974). For stained samples it is possible to divide the results into several categories.

a. stained specimens taken as a living assemblage

b. unstained specimens taken as a dead assemblage

c. a total assemblage of living plus dead

Living assemblages. The living assemblage sampled at one instant of time may or may not be in equilibrium with its environment and may or may not be typical of living assemblages over a longer time period. Nevertheless, it is customary to assume that it is both in equilibrium with its environment and that it is representative of a longer time period. These assumptions may be basically valid as a synthesis of such results has shown (Murray, 1973).

Dead assemblages. The dead assemblage is inevitably built up over a long period of time. The composition of the dead assemblage is controlled by a number of factors which include:

a. production and mortality of the living assemblage

b. postmortem changes such as loss or gain through transport, and loss through destruction by biological, physical or chemical means

In general the dead assemblage will record the average of these processes operating over a long period. Although some dead assemblages may be in equilibrium with the depositional environment in which they are found, others may not be so. It is known that in areas of vigorous bottom disturbance by currents, even coarse grained sediments contain very small foraminiferal tests. Such an area is the western English Channel. However, these tests are not in hydrodynamic equilibrium with the environment. They are present partly because they are trapped in the spaces between dead mollusc shells in the 
shell gravels and partly because they are in transit through the area but are caught by sampling. It can also be shown in other areas that there are seasonal changes in the dead assemblages through the seasonal input of freshly dead tests of individual species (Scott \& Medioli, 1980; Murray, in press). Likewise seasonal storms may winnow away or add tests.

It can be seen from these observations that dead and living assemblages from the same area may be similar but should not be identical and indeed may commonly be dissimilar. Some of the relationships between living and dead assemblages have already been explored by Murray (1976).

Total assemblages. The use of the total assemblage is based on the belief that the validity of living assemblages over a period of time ( 1 or more years) is sufficiently great to make meaningless a survey carried out at one time. Therefore, treating live and dead together is thought to be more realistic for the interpretation of the fossil record (Scott \& Medioli, 1980). This concept requires careful consideration.

It has already been suggested above that the dead assemblage is drawn from the living assemblage through the production and mortality of individual species, followed by postmortem modification through transport or destruction of tests. It therefore does not seem logical to take a composite sample which includes both living and dead individuals, i.e. a total assemblage. In human terms, it is like taking a census of both the living population and the dead in the graveyards. We would not consider such figures to be meaningful and there is no reason to suppose that they are so for total assemblages of Foraminifera.

Further difficulties arise when it is considered that the depth of penetration of the sediment sampler will affect the results. Traditionally, samples of the top $1 \mathrm{~cm}$ of sediment are taken. Although foraminifera live at greater depths in some environments, a large proportion live within the top $1 \mathrm{~cm}$ or $2 \mathrm{~cm}$. In very muddy sediments with a thin $(<1 \mathrm{~cm})$ oxidised zone above anoxic black mud, individuals live only in the oxidised layer (Richter, 1964). It follows that taking a sample of standard thick ness $(\mathrm{e} . \mathrm{g} .1 \mathrm{~cm})$ will not overcome this problem.

Another difficulty is that of the ratio of living to dead individuals. It can be inferred that where live outnumber dead, the total assemblage will resemble the live and vice versa. This ratio is itself partly controlled by the depth of penetration of a given sediment sample.

However, although there are many reasons for questioning the validity of total assemblages, numerous authors have presented their results in this way. It is therefore desirable to assess whether any useful conclusions can be drawn from such data. One way of testing this is to work out some simple mathematical models. The author has already presented some three species examples (Murray, 1976) and additional examples are given below.

Model 1. The basic assumptions incorporated in this model are that foraminifera live only in the top $1 \mathrm{~cm}$ of sediment, that the live:dead ratio in the top $\mathrm{cm}$ is $1: 1$ and

Table 1. Model 1, see text for discussion.

\begin{tabular}{crrrrrrrr} 
Species & \multicolumn{2}{c}{ Living } & \multicolumn{2}{c}{ Dead } & \multicolumn{2}{c}{ Total } & $1 \mathrm{~cm}$ & \multicolumn{2}{c}{ Total } & $2 \mathrm{~cm}$ \\
& No. & $\%$ & No. & $\%$ & No. & $\%$ & No. & $\%$ \\
\hline A & 125 & 50 & 87 & 35 & 212 & 42 & 299 & 40 \\
B & 75 & 30 & 50 & 20 & 125 & 25 & 175 & 23 \\
C & 25 & 10 & 13 & 5 & 38 & 8 & 51 & 7 \\
D & 15 & 6 & 0 & 0 & 15 & 3 & 15 & 2 \\
E & 10 & 4 & 15 & 6 & 25 & 5 & 40 & 5 \\
F & 0 & 0 & 30 & 12 & 30 & 6 & 60 & 8 \\
G & 0 & 0 & 30 & 12 & 30 & 6 & 60 & 8 \\
H & 0 & 0 & 15 & 6 & 15 & 3 & 30 & 4 \\
I & 0 & 0 & 8 & 3 & 8 & 2 & 16 & 2 \\
J & 0 & 0 & 2 & 1 & 2 & 1 & 4 & 1 \\
\hline Total & 250 & 100 & 250 & 100 & 500 & 101 & 750 & 100
\end{tabular}

Similarity matrix

$\begin{array}{lcccc} & \text { Living } & \text { Dead } & \text { Total } 1 \mathrm{~cm} & \text { Total } 2 \mathrm{~cm} \\ \text { Living } & - & 64 & 82 & 76 \\ \text { Dead } & & - & 83 & 88 \\ \text { Total } 1 \mathrm{~cm} & & & - & 95 \\ \text { Total } 2 \mathrm{~cm} & & & & -\end{array}$


that no post mortem changes have influenced the dead assemblage. Comparisons are made between the living assemblage, the dead assemblage and two total assemblages for samples $1 \mathrm{~cm}$ thick and $2 \mathrm{~cm}$ thick respectively. The similarity between sample pairs is measured using the index proposed by Sanders (1960, see also Rogers 1976). Model 1 is shown in Table 1. It can be seen that the living and dead assemblages have $64 \%$ similarity. Because the live:dead ratio is high, both the living and dead assemblages closely resemble the total assemblage (76-95\% similarity). The rank order of the first two species in the living assemblage is maintained in the dead and total assemblages. The rank order of the other species is variable. Such a relationship is what might be expected in an area of rapid sediment accumulation. Under such conditions, a study of living, dead or total assemblages will give similar results.

Model 2. The same basic assumptions apply as for Model 1 with the exception that the live:dead ratio is taken as 1:10 (Table 2). It can be seen that the living assemblage has moderate similarity with the dead and total assemblages (64-68\%) whereas the dead assemblage is closely similar to the total assemblages $(97-100 \%)$. This pattern is typical of areas of slow sedimentation and these include some shelf seas, continental slopes and ocean basins. Under these conditions, dead and total assemblages are effectively the same but they differ markedly from the living.

Table 2. Model 2, see text for discussion.

\begin{tabular}{crrrrrrrr} 
& \multicolumn{3}{c}{ Living } & \multicolumn{2}{c}{ Dead } & \multicolumn{2}{c}{ Total $1 \mathrm{~cm}$} & \multicolumn{2}{c}{ Total $2 \mathrm{~cm}$} \\
Species & No. & $\%$ & \multicolumn{1}{c}{ No. } & \multicolumn{1}{c}{$\%$} & No. & $\%$ & No. & $\%$ \\
\hline A & 125 & 50 & 870 & 35 & 995 & 36 & 1865 & 35 \\
B & 75 & 30 & 500 & 20 & 575 & 21 & 1075 & 20 \\
C & 25 & 10 & 130 & 5 & 155 & 6 & 285 & 5 \\
D & 15 & 6 & 0 & 0 & 15 & 1 & 15 & 0 \\
E & 10 & 4 & 150 & 6 & 160 & 6 & 310 & 6 \\
F & 0 & 0 & 300 & 12 & 300 & 11 & 600 & 12 \\
G & 0 & 0 & 300 & 12 & 300 & 11 & 600 & 12 \\
H & 0 & 0 & 150 & 6 & 150 & 5 & 300 & 6 \\
I & 0 & 0 & 80 & 3 & 80 & 3 & 160 & 3 \\
J & 0 & 0 & 20 & 1 & 20 & 1 & 40 & 1 \\
\hline Total & 250 & 100 & 2500 & 100 & 2750 & 100 & 5250 & 100
\end{tabular}

Similarity matrix

$\begin{array}{lcccc} & \text { Living } & \text { Dead } & \text { Total } 1 \mathrm{~cm} \text {. Total } 2 \mathrm{~cm} \text {. } \\ \text { Living } & - & 64 & 68 & 64 \\ \text { Dead } & & - & 97 & 100 \\ \text { Total } 1 \mathrm{~cm} & & & - & 97 \\ \text { Total } 2 \mathrm{~cm} & & & & -\end{array}$

\section{DISCUSSION AND CONCLUSIONS}

Recently, Scott \& Medioli (1980) carried out a study of seasonal changes in the living and total assemblages of a Nova Scotia salt marsh. They found that, although the living assemblages showed marked variability, the total assemblages were much less variable. Hence, they concluded that the total assemblage '....integrates the small seasonal and spatial variations into a definable assemblage that reliably reflects prevailing marine conditions.' To be fully objective, instead of presenting just living and total assemblage results, they should also have included dead assemblage results. Their text-fig. 5 shows that, in general, the total assemblage is 4 to 6 times larger than the living, i.e. the living: dead ratio is $1: 4$ to $1: 6$. Hence, their results resemble those of Model 2 , namely that the dead and total assemblages are very similar. It seems clear that the concept of the total assemblage is based on false reasoning. It is equally clear that the statement by Scott \& Medioli (1980, p. 830) that 'Paleoenvironmentalists have no choice but to examine buried total populations; therefore, it is indeed fortunate that their only modern analogue is also their best' is completely misleading. Truly ecological studies can be carried out only on living assemblages, ideally studied over a period of time. This will help to determine the relationships between the living assemblages and the dead assemblages drawn from them. Further modification of the dead assemblages will take place through diagenesis after burial. Palaeoecologists should be aware of all these problems when applying the results of ecology to the interpretation of palaeoecology. 


\section{ACKNOWLEDGEMENTS}

Miss $\mathbf{J}$. Weston kindly offered critical comment and Mrs. G. Wright typed the manuscript.

\section{REFERENCES}

Murray, J.W. 1973. Distribution and ecology of living benthic foraminiferids. $288 \mathrm{pp}$. Heinemann, London.

Murray, J.W. 1976. Comparative studies of living and dead benthic foraminiferal distributions. In Hedley, R.H. \& Adams, C.G. (Eds.), Foraminifera, 2, 45-109, London.

Murray, J.W. in press. Population dynamics of benthic Foraminifera: results from the Exe estuary, England. J. foramin. Res.
Richter, G. 1964. Zur Okologie der Foraminiferen II. Lebensraum und Lebensweise von Nonion depressulum, Elphidium excavatum und Elphidium selseyense. Natur und Museum, Frankfurt, 94, 421-430.

Rogers, M.J. 1976. An evaluation of an Index of Affinity for comparing assemblages, in particular of Foraminifera. Palaeontology, London, 19, 503-515.

Sanders, H.L. 1960. Benthic studies in Buzzards Bay III. The structure of the soft-bottom community. Limnol. Oceanogr., Baltimore, 5, 138-153.

Scott, D.B. \& Medioli, F.S. 1980. Living vs. total foraminiferal populations: their relative usefulness in paleoecology. J. Paleont. Chicago, 54, 814-831.

Walker, D.A., Linton, A.E. \& Schafer, C.T. 1974. Sudan Black B: a superior stain to rose Bengal for distinguishing living from non-living Foraminifera. J. foramin. Res., Washington D.C., 4, 205-215.

Walton, W.R. 1952. Techniques for recognition of living Foraminifera. Contr. Cushman Fdn. foramin. Res., Sharon, 3, 56-60. 